\title{
Battery Electric Bus Deployment Considerations in Developing Countries
}

\section{Introduction}

Low-cost solar and wind are increasingly powering the electricity sector of developing countries worldwide. But for countries to fulfill their greenhouse gas emissions, air quality, and other environmental goals, they must also consider changes to the transportation sector. Transportation emissions contribute to about $23 \%$ of carbon dioxide $\left(\mathrm{CO}_{2}\right)$ gas emissions globally, as shown in Figure 1 (ICCT 2014; IPPC 2014). Black carbon, produced by diesel buses, is the secondhighest contributor to transport emissions. Electrifying the transportation sector may help countries achieve their sustainability goals. There are numerous approaches to electrification of the transportation sector, including deployment of battery electric buses (BEBs). BEBs can improve air quality (particularly in urban areas), may help curb greenhouse gas emission, encourage public transit ridership (i.e., reducing traffic congestion) and can have positive impacts on public health and the quality of life for city inhabitants. Energy production is shifted to stationary electrical power plants, often located outside cities. Moving the source to a few stationary power plants (as opposed to many tailpipes) may make emissions easier to control. Electric buses may have other benefits, such as lower noise pollution and potential for improved grid services.

Effective deployment of electric buses requires careful, upfront planning and technology considerations, and several questions must be answered for success:

\section{- Route and application/duty-} cycle: What routes are best suited for electrification? What are the criteria for selecting priority routes? Can electric buses meet the route requirement? Could routes be modified to take better advantage of BEB attributes? When will charging be done - throughout the day along the route or at night at a maintenance garage? Or both?

- Vehicle Specifications: What combination of batteries or other technologies will meet the route/ application requirements? What do you need to support cabin heating and cooling? When will charging happen and what does that mean for battery size?

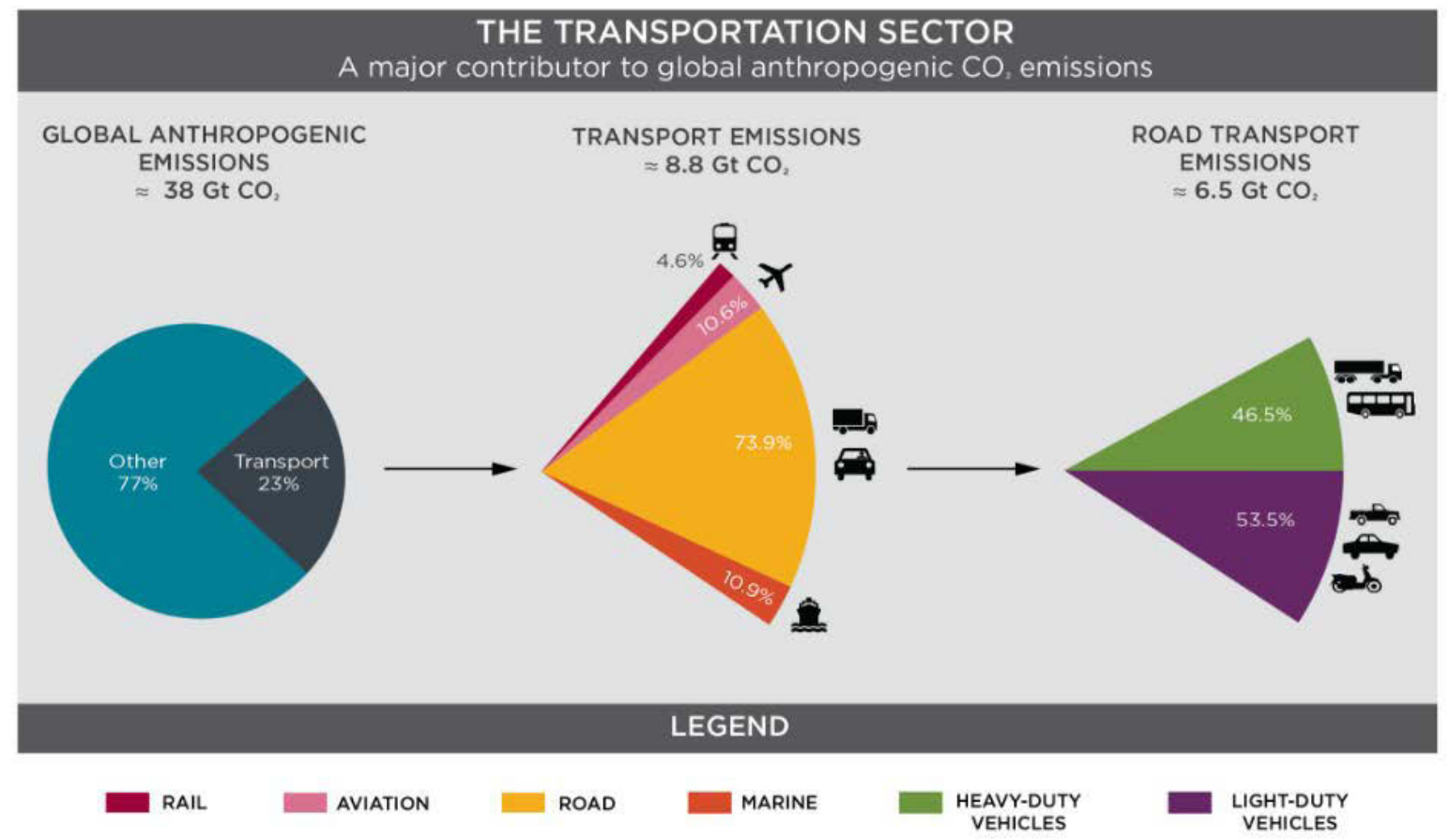

Figure 1. Global $\mathrm{CO}_{2}$ emissions of the transportation sector (ICCT 2014) (IPPC 2014) 
Case Study \#1: Mexico City and Leon Technical Analysis

In September 2017, the National Renewable Energy Laboratory (NREL) conducted a technical analysis to evaluate the potential for transit bus electrification in Mexico City (CDMX) and Leòn. NREL installed GPS and Controller Area Network signals in each bus to collect the bus route data. Using the Future Automotive Systems Technology Simulator (FASTSim) model and vehicle information from the data loggers and bus depot records, NREL analyzed the energy consumption and fuel economy (i.e., efficiency) of conventional diesel buses and battery electric alternatives given the conditions (e.g., speed, distance, number of stops) of the specific routes in CDMX and León. The data showed that Mexico City's routes are more aggressive than observed U.S. routes, with more frequent stops and slower speeds; however, this is conducive to electrification with energy recapture and minimal drag losses, respectively. Thus, bus electrification in Mexico City looks promising.

- Maintenance: Is the jurisdiction prepared for operation and maintenance? Will there need to be retraining of maintenance staff? What level of support for maintenance and technical support is provided by the vehicle manufacturer?

Do your maintenance facilities need any modifications to support BEB?

- Infrastructure: Is the grid infrastructure in place? Is there enough electrical throughput to meet peak charging loads? What on-site or near-site grid upgrades are required? What is the pricing structure for the electricity, and will the peak energy use coincide with peak electricity pricing?

If it helps with meeting their goals, policymakers can enable and encourage the adoption of electric buses. There are several important considerations and technical analyses that may be required to design effective polices or implementation strategies. Many factors, including vehicle duty cycle and the route, can affect the vehicle efficiency and may

\section{Mexico Fuel Economy Validation}

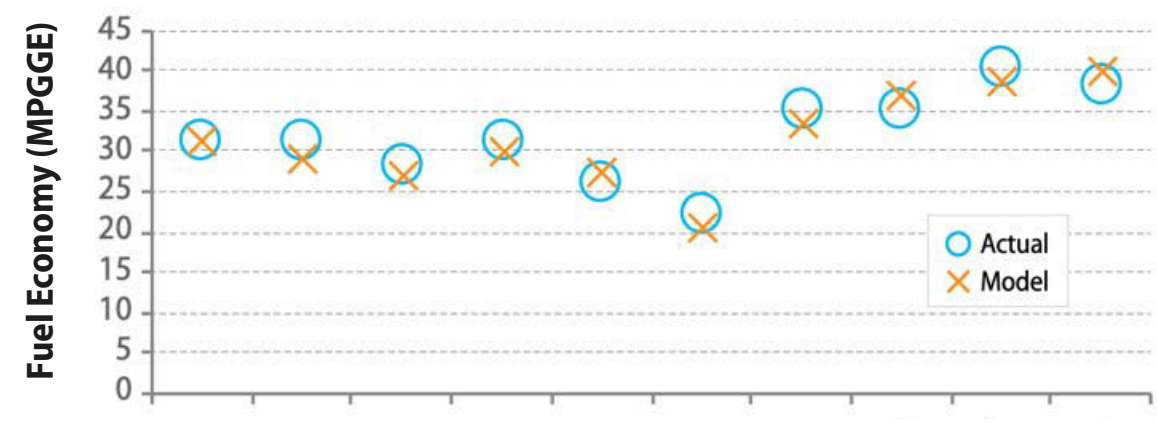

Figure 2. FASTSim sample validation results for a variety of vehicles in Mexico (NREL 2018) Note: Miles per gallon gasoline equivalent (MPGGE) is a measure of the average distance traveled per unit of energy consumed.

differ from the manufacturer's reported performance-including efficiency $(\mathrm{kWh} /$ $\mathrm{km})$ and driving range (kWh/day). Also, electric bus scale-up requires significant planning, such as optimal infrastructure, charging equipment, and distribution grid management considerations.

\section{BEB Considerations}

The following sections step through the six essential BEB considerations: (1) implementation planning; (2) technology selection; (3) economic impacts; (4) charging infrastructure; (5) operational; and (6) maintenance.

\section{Implementation Planning}

Upfront planning and analysis for electric buses is crucial because bus manufacturers quote efficiency $(\mathrm{kWh} / \mathrm{km})$ and range $(\mathrm{km})$ depending on a specific set of route and driving conditions, which can be misleading when they are not representative of local conditions. To select potential routes, first consider route distance, speed, acceleration/ deceleration rates, number of passengers, number of stops, and road grade. In addition, it is essential to understand the charging options for the selected routes by answering these two questions: Will the buses charge at the depot (e.g., standard charge) or will there be an on-route fast charge station? Or perhaps a combination of both will be used? Tools such as FASTSim can help validate how BEB fuel economy, measured in miles per gallon gasoline equivalent (MPGGE), compares for the expected route conditions and is quite accurate, as shown in Figure 2.
During the initial planning period, stakeholders must be engaged early, including fleet managers, maintenance staff, facility managers, and the utility company. Understanding electricity rates (i.e., utility base rates, specific electric vehicle rates, seasonal rate fluctuations, and demand charges) and diesel fuel prices is also important in the early stages of planning.

\section{Technology Selection}

Within the technical considerations, the objective is to develop bus specifications that meet the performance requirements. Thus, it is important to conduct analysis and modeling on key factors: (1) Energy consumption and battery sizing considerations; (2) Bus configuration; and (3) Charging strategies. Battery sizing is based on energy consumption and expected charging strategy. Energy consumption considerations include route options, how the staff drives the bus, the weight of the bus plus passenger loads, and whether heating or air conditioning is continuous, seasonal or not available. Bus configuration is important; it determines the number of batteries needed based on weight and power usage. Charging strategies include overnight depot charging, or on-route fast charging, or a combination of the two. Charging strategies will depend on energy consumption, availability of land, and length of the routes. Also, factors such as the possibility of battery capacity loss over time and the significant impact heating or cooling may have on battery sizing should be considered when determining a charging strategy. 


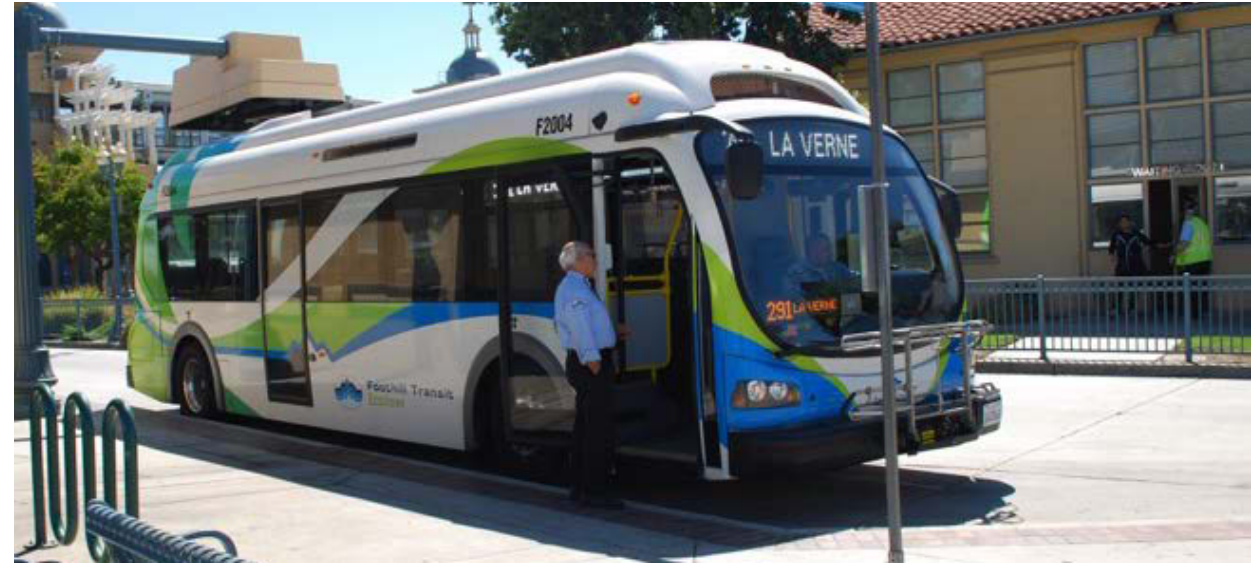

Figure 3. Foothill transit charging station on-route in Southern California, September 2014 (Photo by Leslie Eudy/NREL)

\section{Case Study \#2: Foothill Transit, West Covina, California}

In April 2014, BEB service in West Covina, California, began. Foothill Transit collaborated with the California Air Resources Board and NREL to evaluate and compare performance and operating costs of 12 BEB 35-ft fast charge, 2 BEB 40 -ft fast charge, and 8 North American Bus Industries 42-ft compressed natural gas (CNG) buses between 2014 through 2020. Foothill Transit serviced a completely electric bus route on Line 291. During peak hours, the line required seven buses on the 16.1-mile route with an average speed of 10.6 miles per hour ( $\mathrm{mph}$ ). The additional seven BEBs were used as spares during maintenance. After working with the City of Pomona, two on-route fast chargers were installed allowing buses to fully charge in under 10 minutes. To accommodate time to charge the buses, the bus schedule was adjusted. After analysis, NREL determined that the BEB buses' fuel efficiency was eight times higher than the CNG buses.

(Eudy and Jeffers 2017)

\section{Economic Impacts}

There are costs for electric buses that differ from conventional diesel buses. A few costs to consider include: (1) Upfront capital cost of the buses, batteries, and charging infrastructure; (2) Available incentives and economic mechanisms (e.g., low-interest loans and government subsidies); (3) Electricity pricing strategies; (4) Upgraded electric distribution infrastructure to support electric bus demand; and (5) Bus and battery maintenance costs. On average, the purchase price of a BEB is $\$ 887,000$ and $\$ 480,000$ for a diesel bus. However, over the lifespan of the bus, the total maintenance costs of a diesel bus is about $\$ 1.1$ million, whereas a BEB total maintenance cost is a little under $\$ 700,000$ (Johnson et al. 2020). While some BEB costs are higher and some are lower than diesel buses, all must be considered simultaneously to understand the economics of BEBs. For more financial analysis of BEBs, visit Johnson et al. 2020.

\section{Charging Infrastructure}

Charging infrastructure considerations are essential as cities must determine the best placement of chargers (i.e., depot or on-route) and the number of chargers (i.e., one for each bus or multiple and shared between buses). In addition, the grid may need to be evaluated to determine if it can sustain the power needed for the electric buses and what upgrades may be required to improve the grid if it is not adequate. Other considerations include evaluating the need for an additional transformer, and who owns the electricity or property rights of the on-route charging. Significant grid upgrades could be avoided through appropriate siting of charging infrastructure.

\section{Operational}

BEB operations will require additional training and retraining of current bus drivers (i.e., operators). It is important to address specific driving styles and special operation procedures including safety training for first responders (i.e., awareness of high voltage on board and safety features). In addition, electric buses may require manual hookups to chargers and charging equipment maintenance.

\section{Maintenance}

Maintenance staff will require specialized training (i.e., high-voltage safety) to maintain worker and equipment safety. Maintenance costs will increase once the warranty period of the bus has expired, but this should subside as workers become familiar with technology differences. Also, maintenance requirements will require additional workforce training, as there will be specific tools for troubleshooting and diagnosing issues with advance systems and inventory. It is vital to train the maintenance staff on the bus model, high-voltage electric systems, and any additional follow-up training needed.

\section{Case Study \#3: King County Metro, Seattle, Washington}

In 2010, King Country Metro received funding from the U.S. Federal Transit Administration (FTA) to support the research, development and demonstration of low-and zero-emission technology for transit buses. FTA collaborated with NREL and conducted evaluations of the Proterra, 40ft Catalyst BEB fleet in Seattle, Washington, in 2016. The baseline fleet comparison for the evaluation included 10 diesel hybrid buses, 3 standard diesel buses, and 10 electric trolley buses. The BEBs traveled an average of 14.8 $\mathrm{mph}$ on route 226 and 241 which is an approximately 18.6 mile loop from the Bellevue area east of Seattle. The routes overlap where the buses can charge at the fast charger located at the Eastgate Park and Ride lot. Though the energy and fuel economy varied by season, the BEB fleet had twice the fuel efficiency than that of the hybrid and diesel buses.

Through the evaluation, King County Metro and NREL determined that the availability of on-route, fast-charging was important for optimal operation of BEB fleets. Due to the short range of these buses, additional charging stations were necessary. An adjustment to the bus schedule was also required to allow adequate time to fully charge the buses during planned layovers. Additional operator trainer was essential so that each operator understood and learned the proper charger docking procedure and ensured buses were fully charged before returning to depot.

(FTA and NREL 2018) 


\section{Conclusion}

Successful implementation of electric buses requires careful planning and analysis for the new technology to perform optimally. These six considerations will help jurisdictions have a smoother transition from diesel buses to electric buses and assist in the electric bus policy development and implementation for stakeholders and decision makers. While this guide offers in introduction to BEB considerations, more detailed planning and analysis will be needed for successful implementation. For more information on vehicle electrification, visit the Electric Vehicle (EV) toolkit on Greening the Grid.

\section{References}

Eudy, Leslie, and Matthew Jeffers. 2019. "Foothill Transit Agency Battery Electric Bus Progress Report Data Period Focus: Jan. 2019 through Jun. 2019." Golden, CO: NREL. NREL/PR-5400-73516. https://www.nrel.gov/docs/fy20osti/73516.pdf.

FTA, and NREL. 2018. “Zero-Emission Bus Evaluation Results: King County Metro Battery Electric Buses.” Federal Transit Administration. https://www.transit.dot.gov/sites/fta.dot.gov/files/docs/research-innovation/115086/zero-emission-bus-evaluationresults-king-county-metro-battery-electric-buses-fta-report-no-0118.pdf.

FTA, and NREL. 2017. "King County Metro Battery Electric Bus Demonstration—Preliminary Project Results.” Golden, CO: NREL. DOT/FTA-ZEB-FS1-May 2017. https://www.nrel.gov/docs/fy17osti/68412.pdf.

ICCT. 2014. "Global Transportation Roadmap | International Council on Clean Transportation.” https://theicct.org/series/ global-transportation-roadmap.

IPCC. 2014. Summary for Policy Makers. Climate Change 2014, Intergovernmental Panel on Climate Change. https://www.ipcc.ch/site/ assets/uploads/2018/02/ipcc_wg3_ar5_summary-for-policymakers.pdf.

Janseen, Nicole A.H., Miriam E. Gerlofs-Nigland, Timo Lanki, Raimo O. Salonen, Flemming Cassee, Gerard Hoek, Paul Fishcer, Bert Brunekreef, and Mical Kryzyzanowski. 2012. Health Effects of Black Carbon. Copenhagen, Denmark: WHO Regional Office of Europe. http://www.euro.who.int/_data/assets/pdf_file/0004/162535/e96541.pdf.

Johnson, Caley, Erin Nobler, Leslie Eudy, and Matthew Jeffers. 2020. Financial Analysis of Battery Electric Transit Buses. Golden, CO: National Renewable Energy Laboratory. NREL/TP-5400-74832. https:/www.nrel.gov/docs/fy20osti/74832.pdf.

Kelly, Sarah. 2016. “A World of Thoughts on Phase 2 | International Council on Clean Transportation.” https://theicct.org/blogs/ staff/a-world-of-thoughts-on-phase-2.

Ritchie, Hannah, and Max Roxer. 2020. " $\mathrm{CO}_{2}$ and Greenhouse Gas Emissions.” OurWorldInData.org. https://ourworldindata.org/ co2-and-other-greenhouse-gas-emissions.

Sims R., R. Schaeffer, F. Creutzig, X. Cruz-Núñez, M. D’Agosto, D. Dimitriu, M.J. Figueroa Meza, et al. 2014. 2014: Transport. In: Climate Change 2014: Mitigation of Climate Change. Contribution of Working Group III to the Fifth Assessment Report of the Intergovernmental Panel on Climate Change. Cambridge University Press, Cambridge, United Kingdom. https://www.ipcc.ch/site/assets/ uploads/2018/02/ipcc_wg3_ar5_chapter8.pdf.

Written by Kamyria Coney and Karlynn Cory, National Renewable Energy Laboratory

\section{www.greeningthegrid.org | www.nrel.gov/usaid-partnership}

This work was authored, in part, by the National Renewable Energy Laboratory (NREL), operated by Alliance for Sustainable Energy, LLC, for the U.S. Department of Energy (DOE) under Contract No. DE-AC36-08GO28308. Funding provided by the United States Agency for International Development (USAID) under Contract No. IAG-17-2050. The views expressed in this report do not necessarily represent the views of the DOE or the U.S. Government, or any agency thereof, including USAID.

Greening the Grid is a platform for expertly curated information, tools, and technical assistance to support countries in power system transformation and grid modernization. Greening the Grid is supported by the U.S. Agency for International Development.

The USAID-NREL Partnership addresses critical challenges to scaling up advanced energy systems through global tools and technical assistance, including the Renewable Energy Data Explorer, Greening the Grid, the International Jobs and Economic Development Impacts tool, and the Resilient Energy Platform. More information can be found at: www.nrel.gov/usaid-partnership.

USAID

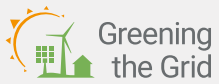

INREL

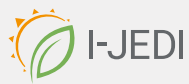

Resilient Energy 